\title{
EXPLORING THE SOUTH AFRICAN PHYSICAL SCIENCES PRE-SERVICE TEACHERS PEDAGOGICAL ORIENTATIONS
}

\author{
Aviwe Sondlo, \& Umesh Ramnarain \\ University of Johannesburg, (South Africa)
}

\begin{abstract}
The most essential aspect of teacher education is to attain different way of teaching science for learner's conceptual understanding. However, in most South African universities, science methodology modules do not fully expose pre-service teachers to different science teaching approaches. In these modules, pre-service teachers often are exposed to readings materials, observing one another in microteaching or create lesson plans for assessment purposes. To teach science effectively, teachers are encouraged to possess a good content knowledge and knowledge of how to translate content knowledge into appropriate teaching ways for specific topic. The study investigates physical science pre-service teacher's pedagogical orientations in one of the South African universities. The phrase 'orientation' refers to teachers' knowledge and beliefs for teaching science. Literature shows various classifications of pedagogical orientations. Based on research conducted in South Africa, orientations are classified into two approaches, namely direct approaches divided into direct didactic and direct interactive and a second approach is an inquiry approach divided into guided inquiry and open discovery. A qualitative method approach was adopted to obtain teachers pedagogical orientations using a questionnaire from the University of Western Michigan. The questionnaire comprised of 10 items and each item has four alternative teaching methods, students were requested to select the most appropriate and the most inappropriate options. For this paper, only the most appropriate teaching orientations were analysed and only two items were analysed, physics and a chemistry item. A descriptive statistics analysis was used. We then calculated a percentage distribution to the four teaching orientations. For calculation purpose, we arbitrarily ordered the spectrum of orientations along a scale of $1-4$, where $1=$ didactic direct; $2=$ direct interactive; $3=$ guided inquiry and $4=$ open inquiry. The results show that pre-service teachers exhibited a preference for learner-centered teaching method, which is centered within guided inquiry for both items.
\end{abstract}

Keywords: Pedagogical orientation, pre-service teachers, inquiry-base.

\section{Introduction}

Researchers around the world in science education for many years debated over the merits about the importance of 'inquiry base and direct' teaching approaches (Coberna, Schuster, Adamsa, Applegatea, Skjolda, Undreiub, Lovingc \& Gobertd, 2010). However, there is a strong opinion on both sides for these teaching approaches. For many years in South Africa, the focus was more on teacher-centred or direct teaching approaches than the inquiry approaches up until the introduction of the new national curriculum referred to as the Curriculum Assessment Policy Statement (CAPS) and Inquiry-based was one of the teaching methods that were advocated. Inquiry-based approach is a strategy that is employed in education where learners/students follow methods and practices similar to those of professional scientists when constructing knowledge (Keselman, 2003). Students are expected to discover new knowledge on their own where a teacher act as a facilitator, learner formulate hypotheses and testing them by making observations or conducting investigations (Pedaste, Mäeots, Leijen, \& Sarapuu, 2012). Inquiry-based stresses active participation and learner's responsibility for discovering knowledge that is new (de Jong \& van Joolingen, 1998).

However, various countries around the world, adopted inquiry base approach long time before South Africa emphasized its importance in the school curriculum and teacher preparation programs in most universities (Crawford, 2014). In some countries education systems in-service teachers and pre-service teachers are encouraged to use teaching approaches that are learner-centred to maximise learning opportunities. Cobern, Schuster, Adams, Skjold, Muğaloğlu et al., (2014) asserts that the important aspect of teacher education to develop pre-service teacher to acquire different ways of teaching 
science for conceptual understanding. Therefore, this study investigate a key dimension in science teaching that will assist in the implementation of inquiry-based approach in teaching which is referred to as teacher's pedagogical orientations. The phrase 'orientation' insinuates teachers' knowledge and beliefs about the purposes and goals of teaching science at a particular grade level (Magnusson, Krajcik, $\&$ Borko, 1999). There are different types of orientations investigated in the literature.

Since South Africa emphasized the importance of inquiry-based, it is of the essence to evaluate the pedagogical orientations physical sciences pre-service teachers assume towards their own classroom teaching when they are teaching during their school teaching experience. The aim of this study was to explore the pedagogical orientations of physical science pre-service teachers' using a multiple-choice questionnaire. To achieve the above aims of the study, the following research question was set:

i. What are the preferred pedagogical orientations of physical science pre-service teachers towards their own teaching?

We administered questionnaires to the physical science pre-service teachers in our university to determine their pedagogical orientations using an existing pedagogical orientation instrument in the form of standardized Multiple-Choice Question (MCQ) format developed by (Cobern, et al., 2014).

Pedagogical Content Knowledge (PCK) underpins the study. PCK is a blend of pedagogical and content knowledge that formulates the transformation of the two knowledge into most powerful, teachable forms to formulate subject and make it comprehensible for learners understanding (Shulman, 1987). PCK emphasises the significance of representation and understanding of content knowledge, it distinguishes science teachers from scientist's knowledge given that science teacher knowledge is different from scientists' knowledge in terms of organization. Science teachers organise their content knowledge in various forms learners can understand, while scientists have specialised knowledge and their knowledge is to develop new things or transform the universe (Cochran, 1998). Within PCK, Magnusson, Krajcik, and Borko (1999) identified a key aspect in teaching and they referred to it as teacher's orientations. Teacher's orientations are "teacher's knowledge and beliefs about the purposes and goals of teaching science at a particular grade level" (p.97). These orientations play an important role in shaping teacher's decisions and goals for science in the classroom.

\section{Pedagogical orientations}

The research on measuring pedagogical orientations of in-service teachers has been conducted around the world and there is a framework that has been developed by a group of the University of Western Michigan researchers. These researchers produced a set of case-based assessment items that present realistic teaching scenarios for most of the science topics (Cobern, et al., 2014). These assessment items are multiple-choice questions but differ from conventional multiple-choice questions in that each of the response options represents a particular pedagogical orientation, rather than a normal MCQ. Cobern et al. (2010) designed a teaching orientation instrument that focuses on the objective of understanding scientific explanations. These items aim to elicit teachers' orientations towards teaching science and encourage the teacher to visualise himself or herself in a teaching situation, play the role of a decision-maker, and respond as if he/she is going to teach that particular lesson.

There are various classifications of pedagogical orientations, based on the research conducted around the by world Anderson and Smith (1987) referred to teaching orientations as various approaches to teaching science and general patterns of teachers' behaviours and thoughts to promote learners' chances of comprehending science concepts. While Magnusson et al. (1999) proposed nine orientations towards science teaching; orientations toward science teaching, academic rigour, didactic, conceptual change, activity-driven, discovery, project-based Science, inquiry, and guided inquiry. Recently, Friedrichsen et al. (2011) reviewed the orientation definitions found in literature and came up with a revised definition that accommodates all previous definitions. Friedrichsen et al. (2011) defined science teaching orientations as a construct that consists of interrelated sets of beliefs teachers hold about the goals or purposes of science teaching, the nature of science and science teaching. This definition of orientations is multidimensional and deals with different facets of teacher beliefs, which in turn affect teacher practice (Campbell, Longhurst, Duffy, Wolf, \& Shelton, 2013). Base on the research conducted in South Africa by Ramnarain and Schuster (2014), they classified orientations into direct didactic, direct active, guided inquiry and open discovery. Ramnarain and Schuster (2014) used Magnusson et al. (1999) teacher orientation definition, however, used a different term 'pedagogical orientations. Below are the four (4) types of orientations and one example of the items used in the questionnaire. 
Figure 1. A description of each of the Pedagogical Orientations adapted from Cobern et al. (2014).

i. A direct didactic approach, a teacher presents and explains the science concept or principle directly to the students and illustrates with examples and/or demonstrations. Students apply this knowledge to questions and problems. There are no or few student practical activities in this method, but there are usually discussions and problems with the content.

ii. A direct interactive orientation similarly entails direct teacher exposition, but this is followed by a student activity based on the presented science content, for example, hands-on practical verification of a law.

iii. In adopting a guided inquiry orientation, the teacher plans an activity where students explore a phenomenon or idea, and from this, the teacher guides them to develop the desired science concept or principle.

iv. In open inquiry, students explore a phenomenon or idea on their own, devising ways of doing so, minimally guided, after which they report what they did and found. The teacher facilitates the student activity but does not intervene more than necessary.

Figure 2 below shows an example of an item used in a questionnaire administered to students.

Figure 2. An example of a teaching Scenario administered to students, Adapted from Cobern et al. (2014).

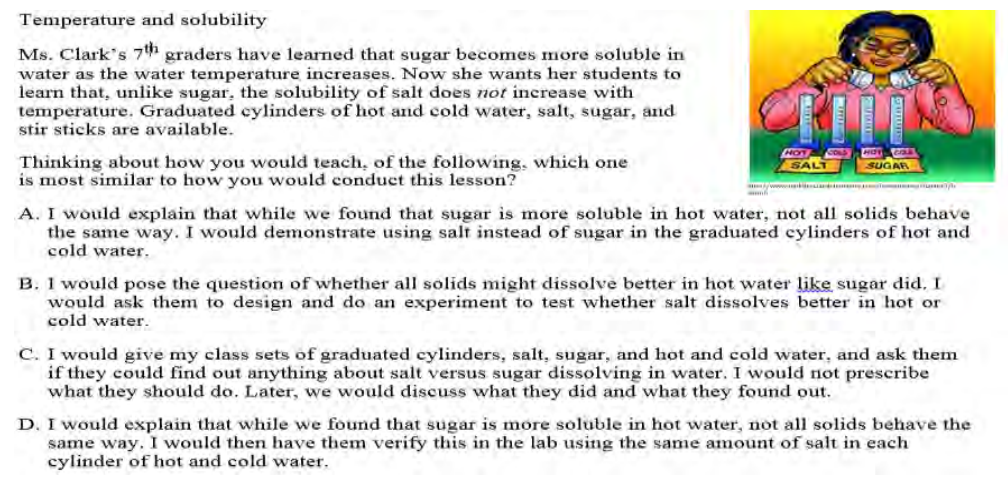

The item presents a practical case, in the form of a teaching vignette describing a realistic teaching situation for a particular topic. The selected item is in a standard multiple-choice question (MCQ.) format as indicated above. At the end of the vignette, the respondent is requested to reflect upon the approach he or she would adopt when teaching this topic. This is followed by four options from which the respondent selects one he/she considers as the most appropriate. Each option corresponds to a pedagogical orientation, namely direct didactic, direct interactive, guided inquiry and open discovery.

\section{Research methods}

We employed a quantitative survey approach; the questionnaire with ten items was administered to all 2018 physical sciences Bachelor of Education final year students at a South African university. For this paper, only two items were analysed due to space or length of the paper. The sample comprised of forty-five students. In their final year of study, students take a year module on the methodology of physical sciences teaching. One of the core themes is to enable students to understand the nature and significance of physical sciences and then develop competencies necessary for successful and effective teaching in physical sciences. Pedagogical Content Knowledge features as a topic within this theme. Throughout the module, students are encouraged to be reflective of their own practice and to justify pedagogical actions taken. Pre-service teachers also do a school practicum that extends for twelve weeks. During this period, a senior teacher at a school mentors one pre-service teacher. The pre-service teachers are expected to design lesson plans, do classroom observations and teach several lessons. We used a descriptive statistics analysis and the percentage distribution of responses to the four teaching options was calculated. For calculation purpose, we arbitrarily ordered the spectrum of orientations along a scale of $1-4$, where $1=$ didactic direct; $2=$ direct interactive; $3=$ guided inquiry and $4=$ open inquiry. Thereafter the coded data were analysed by employing descriptive statistics. Table 1 below reports the pedagogical orientations of pre-service teachers. 


\section{Descriptive results and discussion}

The results of the analysis of quantitative data collected through the questionnaire are presented below. We provide illustrative data comparison between physics and chemistry item responses for pre-service teacher responses to individual items and the overall results for the two items. In each case, we show results for the most preferred pedagogical orientation and display the distributions of responses across the four pedagogical options visually as bar charts. Illustrative data for the two example items given earlier are shown below.

Figure 3. Comparative bar charts for chemistry and physics teacher responses to the most appropriate choices for the two items.

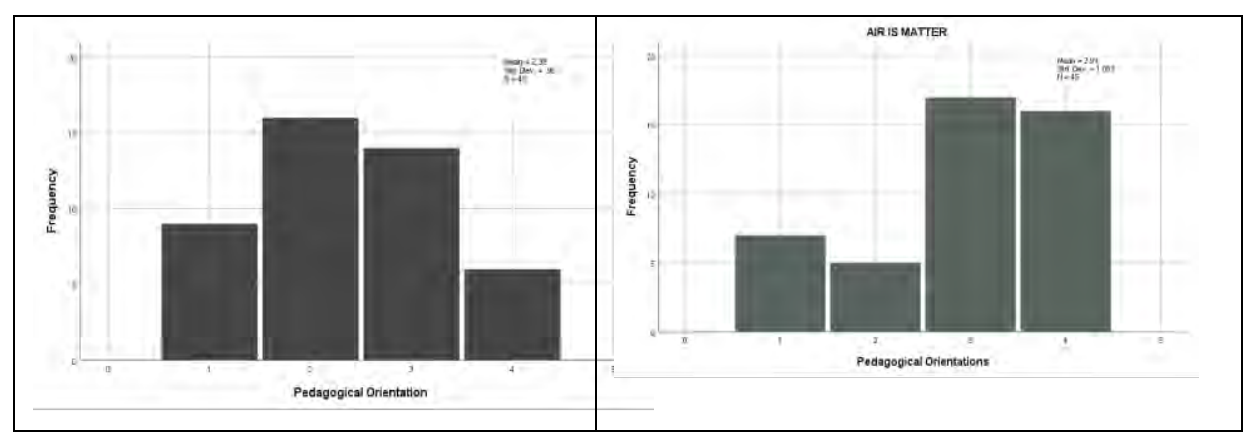

Figures 3 indicates the difference in distributions, for item 1 'acid base indicator', it is evident that direct active was the most appropriate pedagogical orientation among the pre-service teachers. For item 2 'Air is Matter, physical sciences pre-service teachers preferred guided inquiry as a preferred teaching approach. However, several participants selected open discovery as a preferred orientation. But beyond this, for physics items most pre-service teachers preferred orientation lies within teacher cantered modes while physics item lies solely within learner centred mode, this reflecting a clear difference overall between the two items.

\section{Results for the overall questionnaire instrument}

Table 1 presents a comparative result from the overall questionnaire instrument administered to all the physical sciences, pre-service teachers. The table gives the descriptive statistics for pre-service teachers' pedagogical orientations. For each item, the percentage of responses for the four teaching options over the two items is provided.

Table 1. Presents a comparative result from the overall questionnaire instrument.

\begin{tabular}{|l|l|l|l|l|l|l|}
\hline & $\begin{array}{l}\text { Direct } \\
\text { Didactic } \\
(\boldsymbol{\%})\end{array}$ & $\begin{array}{l}\text { Active } \\
\text { Direct }(\boldsymbol{\%})\end{array}$ & $\begin{array}{l}\text { Guided } \\
\text { Inquiry } \\
(\boldsymbol{\%})\end{array}$ & $\begin{array}{l}\text { Open } \\
\text { Inquiry } \\
(\boldsymbol{\%})\end{array}$ & $\begin{array}{l}\text { Mean } \\
\text { score }\end{array}$ & $\begin{array}{l}\text { Standard } \\
\text { deviation }\end{array}$ \\
\hline Acid-Base indicator & 15.6 & 11.1 & 37.8 & 35.6 & 2.93 & 1.053 \\
\hline Air is Matter & 20 & 35.6 & 31.1 & 13.3 & 2.38 & 0.960 \\
\hline $\begin{array}{l}\text { Overall physical sciences pre-service } \\
\text { teachers preferred orientations for the } \\
\text { two items (n=45) }\end{array}$ & 17.8 & 23.35 & 34.45 & 24.45 & 2.65 & 1.0065 \\
\hline
\end{tabular}

The table above shows the pedagogical orientations means scores and std deviations for the two items. The mean score for the first item 'air is matter' is 2.93, this mean the item responses is centered within guided inquiry and the standard deviation 1.053. The mean score for the second item 'acid-base indicator' is 2.38 and lies within direct active and standard deviation 0.960 . The overall mean score for the two items is 2.65 and standard deviation 1.0065 meaning the preferred physical sciences pre-service teachers' pedagogical orientation is guided inquiry for the two items. Below are the two bar graphs that shows the overall preferred pedagogical orientations for the two items.

\section{Discussion and conclusion}

To respond to the research question 'What are the preferred pedagogical orientations of physical science pre-service teachers towards their own teaching?' the results show that pre-service teachers exhibited a preference for learner-centered teaching method which more guided inquiry for is both items. 
For physics item, it was evident that there was a clear distribution of orientations among the students. In South Africa, inquiry-based learning is starting to receive recognition that it deserves from the teacher preparation programs and curriculum developers as the current curriculum emphasise the implementation of inquiry-based classrooms. The results indicate that guided inquiry is the most preferred orientation among the 2018 final year physical sciences pre-service teachers. A guided inquiry orientation is a learner-centred teaching orientation where the teacher plans an activity where students explore a phenomenon or idea, and from this, the teacher guides them to develop the desired science concept or principle. The descriptive statistic tests indicate there is no statistical relationship between the pedagogical orientations while on the other hand the categorical results, the bar graphs show there is a relationship between school type and context. When comparing these results to the findings obtained by Ramnarain and Schuster (2014) study, their findings also revealed differences between the orientations of township teachers and teachers at suburban schools. Township schools' teachers were more centred on active direct teaching orientation overall, while teachers at suburban schools exhibit a guided inquiry orientation.

\section{References}

Anderson, C. W., \& Smith, E. L. (1987). Teaching science. In J. Koehler (Ed.), The educator's handbook: A research perspective (pp. 84-111). New York: Longman.

Campbell, T., Longhurst, M., Duffy, A. M., Wolf, P. G., \& Shelton, B. E. (2013). Science teaching orientations and technology-enhanced tools for student learning in science. Research in Science Education, 43, 2035-2057.

Cobern, W.W., Schuster, D., Adams, B., Applegate, B., Skjold, Undreiu, A. et al. (2010). Experimental comparison of inquiry and direct instruction in science. Research in Science \& Technological Education, 28(1), 81-96.

Cobern, W.W., Schuster, D., Adams, B., Skjold, B.A., Mug alog $\longleftarrow$ lu, E.Z., Bentz. A., \& Sparks, K. (2014). Pedagogy of Science Teaching Tests: Formative assessments of science teaching orientations. International Journal of Science Education, 36(13), 2265-2288.

Cochran, H, K. (1998). Differences in Teachers' Attitudes toward Inclusive Education as Measured by the Scale of Teachers' Attitudes toward Inclusive Classrooms (STATIC). Paper presented at the annual meeting of the Mid-western Educational Research Association, Chicago, Illinois, October 14-16, 1998.

Crawford, B.A. (2014). From inquiry to scientific practices in the science classroom. In N. Lederman \& S. Abell (Eds.), Handbook of research on science education (pp. 515-541). New York: Routledge.

de Jong, T., \& van Joolingen,W. R. (1998). Scientific discovery learning with computer simulations of conceptual domains. Review of Educational Research, 68, 179-202. doi:10.2307/1170753

Friedrichsen, P., Van Driel, J. H., \& Abell, S. K. (2011). Taking a closer look at science teaching orientations. Science Education, 95(2), 358-376.

Keselman, A. (2003). Supporting inquiry learning by promoting normative understanding of multivariable causality. Journal of Research in Science Teaching,40, 898-921. doi:10.1002/tea.10115.

Magnusson, S., Krajcik, L., \& Borko, H. (1999). Nature, sources and development of pedagogical content knowledge. In J. Gess-Newsome \& N. G. Lederman (Eds.), Examining pedagogical content knowledge (pp. 95-132). Dordrecht, the Netherlands: Kluwer.

Pedaste, M., Mäeots, M., Leijen, Ä., \& Sarapuu, S. (2012). Improving students' inquiry skills through reflection and self-regulation scaffolds. Technology,Instruction, Cognition and Learning, 9, 81-95.

Ramnarain, U., \& Schuster, D. (2014). The Pedagogical Orientations of South African Physical Sciences Teachers towards Inquiry or Direct Instructional Approaches. Research in Science Education, 44(4), 627-650.

Shulman, L. (1987). Knowledge and teaching: Foundations of the new reform. Harvard Educational Review, 57(1), 1-22 